\title{
Optimal value commitment in bilateral bargaining
}

Citation for published version (APA):

Britz, V. (2010). Optimal value commitment in bilateral bargaining. METEOR, Maastricht University School of Business and Economics. METEOR Research Memorandum No. 013 https://doi.org/10.26481/umamet.2010013

Document status and date:

Published: 01/01/2010

DOI:

10.26481/umamet.2010013

Document Version:

Publisher's PDF, also known as Version of record

\section{Please check the document version of this publication:}

- A submitted manuscript is the version of the article upon submission and before peer-review. There can be important differences between the submitted version and the official published version of record.

People interested in the research are advised to contact the author for the final version of the publication, or visit the DOI to the publisher's website.

- The final author version and the galley proof are versions of the publication after peer review.

- The final published version features the final layout of the paper including the volume, issue and page numbers.

Link to publication

\footnotetext{
General rights rights.

- You may freely distribute the URL identifying the publication in the public portal. please follow below link for the End User Agreement:

www.umlib.nl/taverne-license

Take down policy

If you believe that this document breaches copyright please contact us at:

repository@maastrichtuniversity.nl

providing details and we will investigate your claim.
}

Copyright and moral rights for the publications made accessible in the public portal are retained by the authors and/or other copyright owners and it is a condition of accessing publications that users recognise and abide by the legal requirements associated with these

- Users may download and print one copy of any publication from the public portal for the purpose of private study or research.

- You may not further distribute the material or use it for any profit-making activity or commercial gain

If the publication is distributed under the terms of Article $25 \mathrm{fa}$ of the Dutch Copyright Act, indicated by the "Taverne" license above, 


\section{Maastricht University}

Volker Britz

Optimal Value Commitment in Bilateral Bargaining

RM/ 10/013

\section{METEOR}

Maastricht University School of Business and Economics

Maastricht Research School of Economics

of Technology and Organization

P.O. Box 616

NL - 6200 MD Maastricht

The Netherlands 


\title{
Optimal value commitment in bilateral bargaining
}

\author{
Volker Britz ${ }^{1}$
}

This version, March 8, 2010

${ }^{1}$ V. Britz (v.britz@maastrichtuniversity.nl), Department of Economics, Maastricht University. The author would like to thank Jean-Jacques Herings and Arkadi Predtetchinski for helpful suggestions and discussions. Financial support by the Netherlands Organization for Scientific Research (NWO) is gratefully acknowledged. 


\begin{abstract}
Two impatient players bargain about the division of a pie under a standard bargaining protocol in discrete time with time-invariant recognition probabilities. Instantaneous utility is linear, but players discount the future by a constant factor. Before bargaining starts, a player can commit to a utility level. This commitment is perfectly binding initially. However, once so much time has passed that even receiving the entire pie would yield less than the committed level of utility, then the commitment becomes void. Intuitively, this simply means that no player can remain committed to something which has become impossible. If only one player can commit, his subgame-perfect equilibrium payoff varies between one half and the entire pie, depending on the distribution of proposal power. If both players commit sequentially before the bargaining starts, we find a unique perfect equilibrium division. If both players commit simultaneously, there is a range of perfect equilibrium divisions. However, no player obtains less than one third of the pie, even with arbitrarily small proposal power. The equal split is the only division supported by a perfect equilibrium for any choice of the discount factor and the recognition probabilities.
\end{abstract}

Keywords: Strategic Bargaining, Commitment, Subgame Perfect Equilibrium.

JEL CODES: C72, D74. 


\section{Introduction}

Two players bargain on how to divide a pie of unit size among themselves. They can only consume the pie once they have agreed on its division. Players are impatient and thus discount future consumption.

We are interested in the ability to commit as a source of bargaining power. We study this question using a notion of commitment with the following two characteristics:

First, the commitment is not expressed as a share of the pie but rather in terms of the pie's time value discounted back to the beginning of the bargaining process. The simple rationale behind this specification is that a commitment should be stated in the terms which the impatient player cares about. Such "value-committing" has been introduced to the literature earlier by Li (2007) and stands in contrast to idea of "share-committing", which is more standard in the literature.

Second, we will assume that the commitment to a certain time value is perfectly binding as long as the pie has at least the committed value. However, as soon as so much time has elapsed that even the receipt of the entire pie would not lead to the committed value anymore, the commitment is assumed to become void. To the best of our knowledge, this notion of commitment is new to the bargaining literature.

Our assumption simply means that we do not allow a player to remain committed to something which is not feasible (anymore). This form of commitment confronts the player with the following dilemma: A high commitment becomes void soon, whereas a low commitment stays in effect for a long time.

It has long been recognized that an irrevocable (and perfectly credible) commitment would be an extremely powerful tool. In fact, if only one player can make such a commitment, the strategic situation would resemble that in an ultimatum game, and the committed player would capture the entire surplus - a result which seems unattractively lopsided. The literature has looked for ways to obtain more attractive or reasonable results by limiting the commitment's credibility. The standard approach which has been taken is to introduce a cost at which a commitment can be revoked. For instance, Muthoo (1992) presents a model of bargaining which generalizes the Nash (1953) demand game as well as Rubinstein's (1982) well-known alternating offer bargaining procedure. The former is seen as a polar case of irrevocable commitments, and the latter as an extreme case of revocable commitments, and the cost of revoking a commitment is used as the parameter scaling between the two. A typical result in this literature is that the player with the higher cost of revoking a commitment has an advantage, see, for instance, Muthoo (1996).

A different well-established approach is that of endogenous commitments. For instance, Fershtman and Seidmann (1993) and Li (2007) consider the possibility that rejecting a proposal commits a player not to accept any worse proposal in the future, an approach which can be motivated by shifts in players' reference points. This approach has been extended and combined with the cost of revoking approach by Calabuig, Cunyat, and Olcina (2002). In Cunyat (2004), a player can choose the strength of his commitment before the bargaining starts. ${ }^{1}$

\footnotetext{
${ }^{1}$ In a different stream of literature, players can be of a fully rational type or of a stubborn type. Stubbornness is then a form of commitment. A typical issue within that literature is the possible incentive of a rational player to try and mimic a stubborn type. Well-known examples are Abreu and Gul (2000)
} 
In what follows, we will study the following game: One out of two players has access to the aforementioned commitment device. That player announces his commitment level. Subsequently, a potentially infinite number of bargaining rounds follows. In each such round, one of the two players is recognized as the proposer by a draw from a time-invariant probability distribution. The proposing player makes an offer and the game ends if it is accepted by the opponent. In case of a rejection the next round starts. However, any consumption in the next round will be discounted by a constant factor $\delta(0<\delta<1)$. In line with our earlier discussion, the commitment device punishes the committed player if he accepts less than his commitment level while the pie's value is still higher than that level. But once the "moment of truth " where the the pie's value shrinks below the commitment level has passed, no punishment is given. One interpretation is that the device punishes "treason "but forgives "failure". Agreeing to less than the commitment while the pie is still sufficiently valuable is akin to giving in to the opponent (treason, weakness), while making an agreement after the moment of truth is giving in to the facts after the failure of an excessively strong bargaining posture. One alternative commitment device would punish the player if he breaks his commitment before the moment of truth, or as soon as the moment of truth is reached. After all, in the latter case it is clear that his promise cannot be fulfilled anymore. It can be shown that this seemingly stronger commitment device does not confer any bargaining power and is therefore not useful. We will see, however, that the more flexible commitment device which we propose, does confer substantial bargaining power.

In any subgame perfect Nash equilibrium of the aforementioned game, we always find immediate and efficient agreement. The subgame-perfect equilibrium division of the pie is unique. If the pie shrinks very rapidly, then the ability to commit is extremely valuable. The committed player can obtain almost the entire surplus even if his proposal power is close to zero. If the pie shrinks very slowly, commitment creates less bargaining power and the recognition probabilities become more important in determining the allocation of the surplus. In the limit as $\delta$ goes to one, proposal power and commitment power are "equally important" in the following sense: If one player can commit and the other player has a recognition probability close to one, then the surplus is shared almost equally.

We present extensions of the model to games where both players can make a commitment before the bargaining starts. If they do so sequentially, then in the limit as $\delta$ goes to one, the first-mover receives a share between one half and two thirds of the pie, depending on the recognition probabilities. With irrevocable and permanent commitment, one would expect the first-mover to obtain the entire surplus.

We also consider the case where players make their commitments simultaneously. With irrevocable and permanent commitment, one would expect all efficient pie divisions to be supported by perfect equilibria irrespective of the value of the discount factor. With the notion of commitment which we suggest, this is no longer true. If the discount factor is chosen sufficiently large, then we find a rather narrow range of efficient divisions which are supported by equilibria. More precisely, the part of the pie whose allocation is left unpredicted by subgame-perfect equilibrium in the limit is at most one fifth. Moreover, a player can never receive less than one third of the pie in a limit equilibrium - even with

and Kambe (1999). In this paper, we do not consider different types of the same player. 
arbitrarily small proposal power. An implication of this finding is that the equal split is the unique division with the property that is is an equilibrium regardless of the parameter choices for the discount factor and the recognition probabilities.

The rest of the paper is organized a follows: In the next section, we formally describe the game in which only a single player can make a commitment. In section 3 , we study the bargaining stage of that game and solve for perfect equilibrium given the choice of commitment. In section 4 , the game as a whole is solved for perfect equilibrium and the optimal commitment is thus derived. In section 5, the game is extended to the case where both players can choose a commitment before the bargaining starts. Again, an analysis of the bargaining stage given the commitment levels is given. The conclusions of section 4 will be essential for this analysis. Section 6 deals with the optimal choice of commitments by both players. Section 7 concludes.

\section{The game with one committed player}

The player set is $N=\{1,2\}$. The two players have a perfectly divisible pie of unit size at their disposal. They consume the pie once they have agreed on its division. Each player's instantaneous utility is equal to his consumption of pie, but future consumption is discounted by a constant and common factor $\delta \in(0,1)$. This implies that at any time $t$, the players can divide among themselves a surplus of value $\delta^{t}$. In the sequel, we will mean by the surplus the time value, discounted to time $t=0$, of the pie to be divided.

The game $G(i)$ consists of a commitment stage and a bargaining stage. The game starts with the commitment stage in which player $i$ chooses a level of commitment $c \in[0,1]$. The ensuing bargaining stage is set in discrete time $t=0,1, \ldots$ At the start of each such round $t$, one player is recognized as the proposer according to the probability distribution $\left(\beta_{1}, \beta_{2}\right)$, where $\beta_{k}>0$ for both $k=1,2$. This player then proposes a division of the surplus, i.e. a pair $\left(x_{1}, x_{2}\right) \in \mathbb{R}_{+}^{2}$ such that $x_{1}+x_{2} \leq \delta^{t}$. If the other player rejects the proposal, round $t+1$ starts. If the other player accepts the proposal, it is implemented and the game ends with the following payoffs for the players:

$$
\begin{aligned}
u_{i}\left(x_{i}, c, t\right) & = \begin{cases}x_{i}-\lambda & \text { if } x_{i}<c \leq \delta^{t} \\
x_{i} & \text { otherwise }\end{cases} \\
u_{j}\left(x_{j}\right) & =x_{j}, j \neq i
\end{aligned}
$$

If players disagree forever, payoffs are zero.

If $c \leq \delta^{t}$, we will say that the commitment $c$ is effective at time $t$. If $c>\delta^{t}$, we say that the commitment $c$ is void at time $t$.

The extensive form of the model admits two different interpretations. The main interpretation we use here is that a pie of size one is available but the players are impatient. Their commitments are expressed in terms of time value rather than the physical surplus. Another interpretation of the model is that a pie of unit size is available initially but physically shrinks by the factor $\delta$ each round, while players are indifferent to the passage of time. With this interpretation, the commitment is expressed in terms of the physical pie and expires as soon as that pie has shrunk below the commitment level. 
If player $i$ agrees to receive less than $c$ while the commitment is still effective, he incurs a cost $\lambda$. We are interested in commitments which are perfectly binding until they expire. Therefore, we assume that $\lambda$ is large enough so that $u_{i}\left(x_{i}, c, t\right)<0$ whenever $x_{i}<c \leq \delta^{t}$. ${ }^{2}$ Thus, perpetual disagreement is better for player $i$ than the violation of his commitment.

We will use subgame perfect Nash equilibrium as the solution concept and proceed by backward induction.

Suppose that in the game $G(i)$, player $i$ has chosen the commitment level $c$ at his initial decision node. Given $c$, the game's bargaining stage will start. We refer to this bargaining stage as the subgame $G(i, c)$, which will be analyzed in the next section. Moreover, we will denote by $G(i, c, t)$ some subgame of $G(i, c)$ in which the chosen commitment level is $c$ and which starts in round $t \geq 1$ of bargaining. Given a bargaining subgame $G(i, c)$ and a round $t$, there are many subgames $G(i, c, t)$, all of which are, however, equivalent with regard to strategies and payoffs.

\section{Subgame perfect bargaining equilibrium}

Define

$$
\tau(c)= \begin{cases}\min \{t \in \mathbb{N} \mid t>\ln (c) / \ln (\delta)\} & \text { if } c>0 \\ 0 & \text { if } c=0\end{cases}
$$

so that in round $\tau(c)$ and all later rounds, the commitment $c$ is void. We will say that the commitment $c$ expires at time $\tau(c)$.

Consider a subgame $G(i, c, t)$ for any $t \geq \tau(c)$. Any such subgame is equivalent to a bargaining game without commitment. In fact, the only difference compared to the game in Rubinstein (1982) is that proposals are not made in an alternating fashion but that the proposer in each round is determined by a fixed recognition probability. In the lemma below, we establish that in such a subgame following the expiry of the commitment, the available surplus is divided in the proportion of the recognition probabilities.

Lemma 3.1 In any subgame $G(i, c, \tau(c))$, player $k$ 's $(k=i, j)$ expected SPE payoff is equal to $\beta_{k} \delta^{\tau(c)}$.

Proof: The same approach as in Shaked and Sutton $(1984)^{3}$ can be applied, as follows: Let $t \geq \tau(c)$ and suppose that $m_{1}(t)\left(M_{1}(t)\right)$ is the infimum (supremum) of SPE payoffs which player 1 can get in some particular subgame $G(i, c, t)$. With probability $\beta_{1}$, player 1 proposes in round $t$. In that case, he may offer player 2 a payoff of $M_{2}(t+1)$. Since no SPE in any subgame $G(i, c, t+1)$ gives player 2 a higher payoff, such an offer will be accepted, and player 1 can secure the payoff $\delta^{t}-M_{2}(t+1)$ for himself. With probability

\footnotetext{
${ }^{2}$ This is ensured for any $\lambda \geq 1$. A different appealing specification is that $\lambda(c)=c$ for any $c$.

${ }^{3}$ Shaked and Sutton consider a deterministic alternating-offer protocol. Their important insight is, however, that a player's SPE payoff "coincides with the sum of shrinkages [of the cake] which occur during these time periods" where that player is the proposer. In the case at hand, we merely apply their insight to the case with a probabilistic proposer protocol.
} 
$\beta_{2}$, player 1 is the responder in round $t$, and he can guarantee himself a payoff of $m_{1}(t+1)$. Formally,

$$
m_{1}(t)=\beta_{1}\left[\delta^{t}-M_{2}(t+1)\right]+\beta_{2}\left[m_{1}(t+1)\right]
$$

A similar consideration explains the supremum, $M_{1}(t)$ : If player 1 proposes in round $t+1$, he can never receive more than $\delta^{t}-m_{2}(t+1)$ in equilibrium, whereas if he is the responder, his SPE payoff is bounded above by $M_{1}(t+1)$. Hence,

$$
M_{1}(t)=\beta_{1}\left[\delta^{t}-m_{2}(t+1)\right]+\beta_{2}\left[M_{1}(t+1)\right]
$$

In $\mathrm{SPE}$, no player will reject in round $t$ any proposal which gives him more than the supremum of his SPE payoffs in a subgame $G(i, c, t+1)$. Consequently, no player will make a proposal which gives him less than the complement of the opponent's supremum payoff in the continuation game. We see that

$$
\begin{aligned}
& m_{1}(t)=\delta^{t}-M_{2}(t) \\
& m_{2}(t)=\delta^{t}-M_{1}(t)
\end{aligned}
$$

Combining with the previous expression for player 1's supremum gives

$$
\begin{array}{rcc}
M_{1}(t) & = & \beta_{1} \delta^{t}(1-\delta)+M_{1}(t+1) \\
& = & \beta_{1} \delta^{t}(1-\delta)+\beta_{1} \delta^{t+1}(1-\delta)+M_{1}(t+2) \\
= & \cdots \\
= & \beta_{1} \sum_{\tau(c)}^{\infty} \delta^{t}(1-\delta) \\
= & \beta_{1} \delta^{\tau(c)}
\end{array}
$$

By the same token, the supremum of SPE payoffs to player 2 in the same subgame is $\beta_{2} \delta^{\tau(c)}$. This implies the values for $m_{1}, m_{2}$. Since it turns out that $m=M$, and since the choice of a particular subgame $G(i, c, t)$ is arbitrary, SPE payoffs in every subgame $G(i, c, t)$ are unique.

By setting a commitment of zero, player $i$ can effectively choose to play the bargaining game without commitment. The previous lemma implies that in an SPE of that bargaining game, the surplus will be divided in the proportion of the recognition probabilities, as stated in the following corollary. We see that the possibility to commit cannot weaken player $i$ 's bargaining position compared to a simple bargaining game without commitment.

Corollary 3.2 If $c=0$, then the SPE payoffs in $G(i, c)$ are $\left(\beta_{1}, \beta_{2}\right)$.

In the next step, we will consider the case where $c>0$ and, furthermore, $c+(1-$ $\left.\beta_{i}\right) \delta^{\tau(c)} \leq 1$. In that case, we define

$$
a(c)=\max \left\{z \in \mathbb{N}_{0} \mid \delta^{z} \geq c+\left(1-\beta_{i}\right) \delta^{\tau(c)}\right\}
$$

In words, round $a(c)$ is the latest round of bargaining in which the amount of pie is sufficient to satisfy player $i$ 's commitment level and player $j$ 's reservation payoff from any subgame $G(i, c, \tau(c))$.

We will make use of the following notion of a player's aspiration. 
Definition 3.3 For any $t=0,1, \ldots$ and $c \in[0,1]$, denote by $r_{k}^{t}(c)$ the highest payoff which player $k=i, j$ receives in any SPE of any subgame $G(i, c, t)$. Then, player $k$ 's aspiration in round $t-1$ is the smallest $x$ such that

$$
u_{k}(x, c, t-1) \geq r_{k}^{t}(c)
$$

The definition is illustrated by the following example. We have shown that in a subgame starting in round $\tau(c)$, player $i$ will receive an SPE payoff of $\beta_{i} \delta^{\tau(c)}$. Now consider round $\tau(c)-1$. By delaying agreement, player $i$ can guarantee himself a utility of $\beta_{i} \delta^{\tau(c)}$, his reservation utility in the conventional terminology. However, in round $\tau(c)-1$, the commitment is still effective. Consequently, player $i$ requires at least an amount of $c$ in order to achieve (and, in fact, surpass) the aforementioned reservation utility. Our model admits a difference between the reservation utility and the minimal surplus allocation needed at a certain point in time to achieve that utility. The latter is what we have defined as the player's aspiration. It plays a crucial role in the next lemma.

Lemma 3.4 Suppose that $c>0$ and $c+\left(1-\beta_{i}\right) \delta^{\tau(c)} \leq 1$. Then, in the subgame $G(i, c)$, player $i$ receives an expected payoff of

$$
\pi_{i}(c)=\beta_{i}+\left(1-\beta_{i}\right) c-\beta_{i}\left(1-\beta_{i}\right) \delta^{\tau(c)}
$$

Proof: Consider any subgame $G(i, c, t)$ such that $a(c)<t<\tau(c)$. In such a subgame, player $j$ can achieve an expected payoff of $\left(1-\beta_{i}\right) \delta^{\tau(c)}$ by delaying agreement until round $\tau(c)$. Similarly, player $i$ can achieve an expected payoff $\beta_{i} \delta^{\tau(c)}$. But in case of an agreement which gives player $i$ some $x_{i}<c$, his payoff will be $u_{i}\left(x_{i}, c, t\right)=x_{i}-\lambda<0$. Consequently, in round $t$, player $i$ will not accept any less than $c$, and player $j$ will not accept any less than $\left(1-\beta_{i}\right) \delta^{\tau(c)}$. But, since $t>a(c)$, we know that $\delta^{t}$ is strictly less than the sum of these two aspirations. Hence, no agreement can be reached in round $t$.

Now consider round $a(c)$. If no agreement were reached at $a(c)$, then delay would result until round $\tau(c)$. In that case, players would receive payoffs of $\beta_{i} \delta^{\tau(c)}$ and $\beta_{j} \delta^{\tau(c)}$. Consequently, their aspirations at $a(c)$ are $c$ and $\beta_{j} \delta^{\tau(c)}$. In a subgame at $a(c)$, SPE requires that the responder receive his aspiration and the proposer take the complement. Hence, player $i$ 's expected SPE payoff in a subgame starting at round $a(c)$ is $\beta_{i}\left(\delta^{a(c)}-\beta_{j} \delta^{\tau(c)}\right)+\beta_{j} c$.

Applying recursive equations to rounds $0,1, \ldots, a(c)-1$ reveals that player $i$ and $j$ will in addition share an amount $1-\delta^{a(c)}$ in the proportion of their recognition probabilities. Then, we have that

$$
\pi_{i}(c)=\beta_{i}\left(1-\delta^{a(c)}\right)+\left(1-\beta_{i}\right) c+\beta_{i}\left(\delta^{a(c)}-\left(1-\beta_{i}\right) \delta^{\tau(c)}\right)
$$

The statement is obtained by rewriting this equation.

As an illustration of the argument in Lemma 3.4, the following figure depicts a timeline where a solid line indicates periods in which an agreement can be reached and dotted lines indicate periods in which delay occurs because the sum of aspirations is higher than the current surplus.

In the case considered in Lemma 3.4 and illustrated by the above timeline, $a(c)$ is well-defined, that is, $c$ is sufficiently small so that an agreement can be reached with the commitment effective. We now turn to the opposite case. 


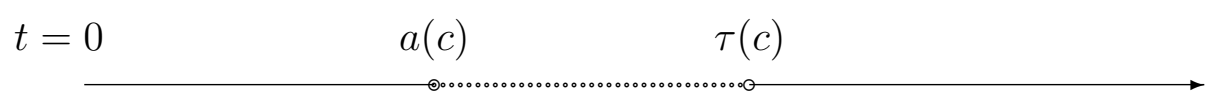

Lemma 3.5 Suppose that $c+\left(1-\beta_{i}\right) \delta^{\tau(c)}>1$. Then, player $k$ 's $(k=i, j)$ expected $S P E$ payoff in the subgame $G(i, c)$ is equal to $\beta_{k} \delta^{\tau(c)}$.

Proof: If $c+\left(1-\beta_{i}\right) \delta^{\tau(c)}>1$, it is impossible to reach agreement before round $\tau(c)$. The statement follows from Lemma 3.1.

The following figure shows the delay until round $\tau(c)$, from which onwards bargaining without commitment takes place on the remaining pie of size $\delta^{\tau(c)}$.

$$
t=\underset{\ldots \ldots \ldots \ldots \ldots \ldots \ldots \ldots \ldots \ldots \ldots \ldots \ldots}{0} \tau(c)
$$

We summarize the results of this section in the following theorem.

Theorem 3.6 Suppose that player $i$ has chosen a commitment level of $c$. Then, all SPE of the corresponding bargaining subgame $G(i, c)$ lead to a payoff for player $i$ given by

$$
\pi_{i}(c)= \begin{cases}\beta_{i}+\left(1-\beta_{i}\right) c-\beta_{i}\left(1-\beta_{i}\right) \delta^{\tau(c)} & \text { if } c+\left(1-\beta_{i}\right) \delta^{\tau(c)} \leq 1 \text { and } c>0 \\ \beta_{i} \delta^{\tau(c)} & \text { if } c+\left(1-\beta_{i}\right) \delta^{\tau(c)}>1 \\ \beta_{i} & \text { if } c=0\end{cases}
$$

In the first and third cases, an efficient agreement is reached immediately, so that $\pi_{j}(c, \delta)=1-\pi_{i}(c, \delta)$. Only in the second case, delay occurs. In that case, player $j$ 's payoff is $\pi_{j}(c, \delta)=\beta_{j} \delta^{\tau(c)}$.

We remark that while SPE payoffs in the bargaining subgame are unique, SPE strategies are not. We have shown that in a round $t$ such that $a(c)<t<\tau(c)$, no agreement is possible, since the sum of players' aspirations exceeds the available surplus. In SPE, no agreement can therefore occur in such a round $t$. However, it is indeterminate which exact proposal is made in round $t$ so long as it will be rejected. For example, suppose that $i$ proposes in round $t$. He may propose any division $(x, 1-x)$ as long as $x$ is at least his aspiration and at most 1. 


\section{Optimal commitment}

In the previous section, we have found player $i$ 's expected SPE payoff in the subgame $G(i, c)$ for any commitment level $c$. Now we proceed by backward induction to the game $G(i)$ and ask which level of commitment player $i$ will choose in SPE. So far, we have not used the assumption that each player has a strictly positive recognition probability. It will become essential in this section.

Lemma 4.1 In any SPE of the game $G(i)$, it is true that $c>0$.

Proof: Since $\lim _{c \downarrow 0}\left[c+\left(1-\beta_{i}\right) \delta^{\tau(c)}\right]=0$, we can find $c^{\prime}>0$ sufficiently small such that $c^{\prime}+\left(1-\beta_{i}\right) \delta^{\tau\left(c^{\prime}\right)} \leq 1$. Then, it follows from Lemma 3.4 that $\pi_{i}\left(c^{\prime}, \delta\right)=\beta_{i}+(1-$ $\left.\beta_{i}\right) c^{\prime}-\beta_{i}\left(1-\beta_{i}\right) \delta^{\tau\left(c^{\prime}\right)}$. By definition of $\tau(c)$, it holds that $c>\delta^{\tau(c)}$ for any $c>0$. If $\beta_{i}<1$, this implies that $\pi_{i}\left(c^{\prime}, \delta\right)>\beta_{i}+\left(1-\beta_{i}\right)^{2} \delta^{\tau\left(c^{\prime}\right)}$, which readily implies $\pi_{i}\left(c^{\prime}, \delta\right)>\beta_{i}$. But by Corollary $3.2, \beta_{i}$ is the payoff to player $i$ from the choice of $c=0$.

Lemma 4.2 In any SPE of the game $G(i)$, it holds that $c+\left(1-\beta_{i}\right) \delta^{\tau(c)} \leq 1$.

Proof: Suppose not. Then, by Theorem 3.6, player $i$ 's SPE payoff in the subgame $G(i, c)$ equals $\beta_{i} \delta^{\tau\left(c_{1}\right)} \leq \beta_{i} \delta$. Player $i$ may deviate from his choice of $c$ to a commitment level of zero. In that case, a payoff of $\beta_{i}>0$ will result. Since $\beta_{i}>\beta_{i} \delta$, this deviation is profitable, a contradiction.

The two previous lemmas show that only the first case mentioned in Theorem 3.6 is relevant in an SPE of the entire game, giving rise to the following corollary.

Corollary 4.3 In any SPE of the game $G(i)$, an efficient agreement is reached immediately. The commitment level $c$ of player $i$ satisfies $c>0$ and $c+\left(1-\beta_{i}\right) \delta^{\tau(c)} \leq 1$. The payoff to player $i$ is given by

$$
\pi_{i}(c, \delta)=\beta_{i}+\left(1-\beta_{i}\right) c-\beta_{i}\left(1-\beta_{i}\right) \delta^{\tau(c)}
$$

and the payoff to player $j$ is $\pi_{j}(c, \delta)=1-\pi_{i}(c, \delta)$.

The expression for player $i$ 's payoff in the above corollary can be rewritten as $\pi_{i}(c, \delta)=$ $c+\beta_{i}\left(1-c-\beta_{j} \delta^{\tau(c)}\right)$, and the concomitant payoff of player $j$ as $\pi_{j}(c, \delta)=\beta_{j} \delta^{\tau(c)}+\beta_{j}(1-c-$ $\left.\beta_{j} \delta^{\tau(c)}\right)$. Hence, given that player $i$ 's commitment $c$ satisfies $c>0$ and $c+\left(1-\beta_{i}\right) \delta^{\tau(c)} \leq 1$, the resulting division of the surplus can be interpreted as follows: Player $i$ obtains his commitment level $c$, player $j$ his resulting aspiration $\beta_{j} \delta^{\tau(c)}$, and the remainder is divided in the proportion of the recognition probabilities - as it would be if there were no commitment. This interpretation makes it intuitively clear that player $i$ should choose the highest $c$ which satisfies the constraint $c+\left(1-\beta_{i}\right) \delta^{\tau(c)} \leq 1$. This result will be derived formally in what follows.

We will now define a particular commitment level $\psi_{i}$ for player $i$ and then prove that it will be chosen in SPE. 


$$
\begin{aligned}
\psi_{i} & =\min \left\{1-\delta^{n^{*}} \beta_{j}, \delta^{n^{*}-1}\right\}, \text { where } \\
n^{*} & =\min \left\{n \in \mathbb{N} \mid \delta^{n}<\frac{1}{1+\beta_{j}}\right\}
\end{aligned}
$$

Intuitively, the idea behind the definition of $\psi_{i}$ is the following: As pointed out before, we want to find the highest $c$ which satisfies $c+\left(1-\beta_{i}\right) \delta^{\tau(c)} \leq 1$. We will show first that this optimal level of $c$ expires at time $n^{*}$. We then conclude that the optimal commitment is bounded above by $\delta^{n^{*}-1}$. (Any higher commitment would expire before $n^{*}$.) This explains the second argument in the minimum function defining $\psi_{i}$. The first argument of the minimum function follows again from the restriction that $c+\left(1-\beta_{i}\right) \delta^{\tau(c)} \leq 1$.

Theorem 4.4 In any SPE of the game $G(i)$, player $i$ commits to $\psi_{i}$. Agreement is reached immediately on the division $\left(\varphi_{i}, 1-\varphi_{i}\right)$, where

$$
\varphi_{i}=\beta_{i}+\beta_{j} \psi_{i}-\beta_{i} \beta_{j} \delta^{\tau\left(\psi_{i}\right)}
$$

Proof: We have shown that in SPE, $c>0$ and $c+\beta_{j} \delta^{\tau(c)} \leq 1$. We will now find the highest level of commitment which satisfies these conditions. We observe first that $c+\beta_{j} \delta^{\tau(c)} \leq 1$ implies $\delta^{\tau(c)}+\beta_{j} \delta^{\tau(c)}<1$, and therefore $\delta^{\tau(c)}<\left(1+\beta_{j}\right)^{-1}$.

Now suppose that in some $\operatorname{SPE} \delta^{-1} \delta^{\tau(c)}+\beta_{j} \delta^{-1} \delta^{\tau(c)}<1$. Let $c^{\prime}=\delta^{-1} \delta^{\tau(c)}+\varepsilon$. If $\varepsilon>0$ is small enough, then $c^{\prime}+\beta_{j} \delta^{\tau\left(c^{\prime}\right)} \leq 1$ holds. But then, Theorem 3.6 implies that a deviation from $c$ to $c^{\prime}$ would be profitable.

We have now shown that in SPE

$$
\begin{aligned}
\delta^{\tau(c)} & \in\left[\delta\left(1+\beta_{j}\right)^{-1},\left(1+\beta_{j}\right)^{-1}\right) \\
\tau(c) & =n^{*} \\
c & \in\left(\delta^{n^{*}}, \delta^{n^{*}-1}\right] \\
c & \leq 1-\beta_{j} \delta^{n^{*}}
\end{aligned}
$$

The second line follows from the first since by construction $n^{*}$ is the only natural number $n \in \mathbb{N}$ such that $\delta^{n}$ lies in the specified interval. The third line follows from the second since $\delta^{\tau(c)}<c$ for any $c>0$ by definition of $\tau(c)$. Finally, the fourth line follows from substituting $n^{*}$ for $\tau(c)$ in the condition $c+\left(1-\beta_{i}\right) \delta^{\tau(c)} \leq 1$.

Under the above conditions, Theorem 3.6 implies that player $i$ 's payoff is given by $\beta_{i}+\beta_{j} c-\beta_{i} \beta_{j} \delta^{n^{*}}$. This expression is strictly increasing in $c$. Hence the optimal level of commitment is the highest $c$ which satisfies the above set of conditions. Indeed, $c=$ $\min \left\{1-\delta^{n^{*}} \beta_{j}, \delta^{n^{*}-1}\right\}$.

The fact that immediate agreement is reached on $\left(\varphi_{i}, 1-\varphi_{i}\right)$ follows from Theorem 3.6.

From the above expressions for $\psi_{i}$ and $\varphi_{i}$, it follows that $\varphi_{i} \in\left(\beta_{i}, 1\right)$. For any $\delta$, player $i$ can (strictly) benefit from the ability to commit compared to the situation without a commitment possibility. However, player $i$ will never receive the entire pie.

We can easily see that in the limit as $\delta \rightarrow 1$, both the SPE commitment $\psi_{i}$ and the SPE payoff $\varphi_{i}$ converge to $\frac{1}{1+\beta_{j}}$, whence the following corollary. 
Corollary 4.5 In the limit as $\delta \rightarrow 1$, the SPE division of the surplus converges to $\left(x_{i}, x_{j}\right)=\left(\frac{1}{1+\beta_{j}}, \frac{\beta_{j}}{1+\beta_{j}}\right)$.

Let us suppose that $\beta_{j}$ is very high. Given that the distribution of proposal power is very favorable to player $j$, can player $i$ compensate for his weakness if he is given the possibility to commit? Corollary 4.5 implies that if $\delta$ and $\beta_{j}$ are both close to one, player $i$ can obtain about one half of the pie. Hence, if $\delta$ is large, the power of one player to commit is just sufficient to compensate for the fact that proposal power is concentrated with the other player. If $\delta$ is small, however, the ability to commit is much more powerful than that. In fact, for $\delta$ close to zero, the player who is able to commit can obtain close to the entire pie even if his proposal power is arbitrarily small. We illustrate these findings with the following numerical example.

Example 4.6 Let $\beta_{j}=0.9$. Suppose first that the discount factor is very small, say, $\delta=0.1$. In that case, we have that $n^{*}=1$, and therefore $\psi_{i}=\min \{1-0.09,1\}=0.91$. The resulting payoff to player $i$ will be $\varphi_{i}=0.1+0.9 \times 0.91-0.1 \times 0.9 \times 0.1=0.91$. Now suppose that $\delta=0.9$, then $n^{*}=7{ }^{4}$ We have $\psi_{i}=\min \{1-0.478 \times 0.9,0.531\}=0.531$. The resulting share of player $i$ is $\varphi_{i} \approx 0.1+0.9 \times 0.531-0.1 \times 0.9 \times 0.478 \approx 0.535$.

We see that for small $\delta$, the implications of our notion of commitment are close to those which one would expect of an irrevocable and everlasting commitment. For large $\delta$, however, the type of commitment which we propose leads to different results. This pattern will be observed more often in the sequel of the paper, when we deal with games in which both players have access to the commitment device.

\section{$5 \quad$ Bargaining with two committed players}

In this section, we will consider a bargaining (sub-) game $G^{B}\left(c_{1}, c_{2}\right)$. In this game, the two players bargain according to the protocol specified earlier for the game $G(i)$. That is, in each round a proposer is determined by the probability distribution $\beta$. However, both players $k=1,2$ are committed and thus have the following utility function.

$$
u_{k}\left(x_{k}, c_{k}, t\right)= \begin{cases}x_{k}-\lambda<0 & \text { if } x_{k}<c_{k} \leq \delta^{t} \\ x_{k} & \text { otherwise }\end{cases}
$$

We will find the SPE payoffs in the game $G^{B}\left(c_{1}, c_{2}\right)$.

Henceforth, we will use $i$ to denote the player with the highest commitment level. That is, we assume without loss of generality that $c_{i} \geq c_{j}$.

Definition 5.1 Suppose both players use the commitment device $\left(c_{j}>0\right)$. We will say that $c_{j}$ expires soon after $c_{i}$ if $c_{j}>\psi_{j} \delta^{\tau\left(c_{i}\right)}$.

\footnotetext{
${ }^{4}$ We note that $0,9^{6} \approx 0.531$ and $0.9^{7} \approx 0.478$. The former is just above the relevant threshold of $\frac{1}{1+0.9} \approx 0.526$.
} 
The condition $c_{j}>\psi_{j} \delta^{\tau\left(c_{i}\right)}$ is equivalent to $c_{j}+\beta_{i} \delta^{\tau\left(c_{j}\right)}>1$. Moreover, if $c_{j}$ is sufficiently small for $a\left(c_{j}\right)$ to be well-defined, then the condition is also equivalent to $\tau\left(c_{i}\right)>a\left(c_{j}\right)$. Intuitively, if $c_{j}$ expires soon after $c_{i}$, it is impossible to reach agreement when $c_{i}$ is already void but $c_{j}$ is still effective. In the sequel, we will find the SPE payoffs by backward induction. The resulting payoff function will distinguish four cases. One distinction is whether $c_{j}$ does or does not expire soon after $c_{i}$. The other distinction is whether or not agreement is possible at $t=0$.

To find the SPE payoffs, let us suppose first that delay lasts until round $\tau\left(c_{j}\right)$, that is, until even the lower of the two (strictly positive) commitments has just expired. Then, the remaining surplus $\delta^{\tau\left(c_{j}\right)}$ will be divided in the proportion $\beta_{i}: \beta_{j}$. The argument is as in Lemma 3.1.

Now go backwards to the situation just before $c_{j}$ expires. Here, player $i$ 's aspiration is $\beta_{i} \delta^{\tau\left(c_{j}\right)}$. But player $j$ is still committed, so that his aspiration is $c_{j}$. If $c_{j}+\beta_{i} \delta^{\tau\left(c_{j}\right)}>1$, no agreement can be reached before round $\tau\left(c_{j}\right)$. If, to the contrary, $c_{j}+\beta_{i} \delta^{\tau\left(c_{j}\right)} \leq 1$, then an agreement before round $\tau\left(c_{j}\right)$ is only possible until round $a\left(c_{j}\right)$, when the surplus is at least $c_{j}+\beta_{i} \delta^{\tau\left(c_{j}\right)}$. The argument is as in Lemma 3.4.

If (and only if) $c_{j}$ expires soon after $c_{i}$ as by Definition 5.1, then player $i$ 's commitment is effective at time $a\left(c_{j}\right)$. Suppose that this is indeed the case. Then, it remains impossible to reach an agreement at $a\left(c_{j}\right)$ since now the aspirations are equal to the commitments and hence the surplus would have to be at least $c_{i}+c_{j}$ for an agreement to occur. Suppose that $c_{i}+c_{j}>1$. Then, it is impossible to find agreement before round $\tau\left(c_{j}\right)$. Formally, we have the following result.

Lemma 5.2 Suppose that commitments are strictly positive, $c_{j}$ expires soon after $c_{i}$, and sum up to strictly more than one. Then SPE payoffs in the bargaining subgame are given by $\pi_{k}=\beta_{k} \delta^{\tau\left(c_{j}\right)}$ for $k=i, j .{ }^{5}$

Continue to suppose that commitments are strictly positive and $c_{j}$ expires soon after $c_{i}$ but suppose now that $c_{i}+c_{j} \leq 1$. We have pointed out previously that no agreement is possible between rounds $a\left(c_{j}\right)$ and $\tau\left(c_{j}\right)$. Moreover, we have seen that at $a\left(c_{j}\right)$ and any earlier round, the aspirations are equal to the commitments. Consequently, once the surplus has shrunk below $c_{i}+c_{j}$, delay until $\tau\left(c_{j}\right)$ will result. Consider round $\tau\left(c_{i}+c_{j}\right)-1$. Here, an agreement can be made. Under this agreement, the responding player will receive exactly his commitment level, whereas the proposing player receives the rest of the available surplus. Continuing backwards from the said round until the start of the game is done easily in a way similar to Lemma 3.1. The following figure provides an illustration of the timeline of bargaining in this case. Again, solid lines represent periods where agreement can be reached.

Formally, we now arrive at the following result:

\footnotetext{
${ }^{5}$ In the main text, we have also discussed the case where the lower commitment $c_{j}$ is so high that $a\left(c_{j}\right)$ is not well-defined. We have pointed out that delay until $\tau\left(c_{j}\right)$ also occurs in that case. Since $c_{j}+\beta_{i} \delta^{\tau\left(c_{j}\right)}>1$ implies $c_{i}+c_{j}>1$, we do not treat this case in a seperate lemma.
} 


$$
t=0 \quad \tau\left(c_{i}+c_{j}\right) \quad a\left(c_{j}\right) \quad \tau\left(c_{i}\right) \quad \tau\left(c_{j}\right)
$$

Lemma 5.3 Suppose that commitments are strictly positive, $c_{j}$ expires soon after $c_{i}$, and $c_{i}+c_{j} \leq 1$. Then, SPE payoffs in the bargaining subgame are given by:

$$
\begin{aligned}
\pi_{i} & =\beta_{i}\left(1-\delta^{\tau\left(c_{i}+c_{j}\right)-1}\right)+\left(1-\beta_{i}\right) c_{i}+\beta_{i}\left(\delta^{\tau\left(c_{i}+c_{j}\right)-1}-c_{j}\right) \\
& =\left(1-\beta_{i}\right) c_{i}-\beta_{i} c_{j}+\beta_{i} \\
& =\left(1-\beta_{i}\right) c_{i}+\beta_{i}\left(1-c_{j}\right)
\end{aligned}
$$

Remark 5.4 Since $\tau(1)=1$, Lemma 5.3 implies that if $c_{j}$ expires soon after $c_{i}$ and $c_{i}+c_{j}=1$, then each player receives a payoff equal to his commitment in equilibrium.

Next, we turn to the case where $c_{j}$ does not expire soon after $c_{i}$. In round $a\left(c_{j}\right)$, player $i$ 's commitment is already void. Therefore, it is possible to reach an agreement at $a\left(c_{j}\right)$. If player $j$ is the responder, he will receive exactly his aspiration $c_{j}$. If player $j$ is the proposer, he obtains the available surplus minus player $i$ 's aspiration $\beta_{i} \delta^{\tau\left(c_{j}\right)}$. Again, continuing backwards until round $\tau\left(c_{i}\right)$ is done in a similar way as in Lemma 3.1.

Formally, we find that player $j$ 's payoff in any subgame starting in round $\tau\left(c_{i}\right)$ will be:

$$
\begin{aligned}
A_{j}\left(c_{i}, c_{j}\right) & =\beta_{j}\left(\delta^{\tau\left(c_{i}\right)}-\delta^{a\left(c_{j}\right)}\right)+\beta_{j}\left(\delta^{a\left(c_{j}\right)}-\beta_{i} \delta^{\tau\left(c_{j}\right)}\right)+\left(1-\beta_{j}\right) c_{j} \\
& =\beta_{j} \delta^{\tau\left(c_{i}\right)}+\left(1-\beta_{j}\right) c_{j}-\beta_{i} \beta_{j} \delta^{\tau\left(c_{j}\right)}
\end{aligned}
$$

The above expression is clearly analogous to Lemma 3.4. A subgame starting at $\tau\left(c_{i}\right)$ is equivalent to a game with one committed player whose commitment is sufficiently small to reach agreement before it expires. We observe that $A_{j}\left(c_{i}, \psi_{j} \delta^{\tau\left(c_{i}\right)}\right)=\varphi_{j} \delta^{\tau\left(c_{i}\right)}$.

In any round $t<\tau\left(c_{i}\right)$, player $j$ will therefore have the aspiration $A_{j}\left(c_{i}, c_{j}\right)$. Obviously, player $i$ 's aspiration is $c_{i}$. Consider the case where $c_{i}+A_{j}\left(c_{i}, c_{j}\right)>1$. Clearly, it is not possible to reach agreement before round $\tau\left(c_{i}\right)$, since in any earlier round the sum of aspirations exceeds the available surplus. Hence, the payoffs from a subgame starting at $\tau\left(c_{i}\right)$ are also the payoffs in the entire game. We depict this situation in a figure, and arrive at the following lemma.

$$
t=0 \quad \tau\left(c_{i}\right) \quad a\left(c_{j}\right) \quad \tau\left(c_{j}\right)
$$

Lemma 5.5 Suppose that commitments are strictly positive and $c_{j}$ does not expire soon after $c_{i}$. Furthermore, suppose that $c_{i}+A_{j}\left(c_{i}, c_{j}\right)>1$. Then, SPE payoffs in the bargaining subgame are given by $\delta^{\tau\left(c_{i}\right)}-A_{j}\left(c_{i}, c_{j}\right)$ for player $i$ and $A_{j}\left(c_{i}, c_{j}\right)$ for player $j$. 
Let us continue to suppose that commitments are strictly positive and $c_{j}$ does not expire soon after $c_{i}$ but now consider the case where $c_{i}+A_{j}\left(c_{i}, c_{j}\right) \leq 1$, which means that an agreement can be reached with both commitments effective. We denote by $b\left(c_{i}, c_{j}\right)$ the round in which the surplus is just sufficient to cover the sum of the aspirations $c_{i}$ and $A_{j}\left(c_{i}, c_{j}\right)$, see figure below.

$$
t=\underset{0}{0} \quad b\left(c_{i}, c_{j}\right) \quad \tau\left(c_{i}\right) \quad a\left(c_{j}\right) \quad \tau\left(c_{j}\right)
$$

Applying the same argument as above, we now find the payoff of player $i$ in the entire bargaining subgame:

$$
\begin{aligned}
\pi_{i} & =\beta_{i}\left(1-\delta^{b\left(c_{i}, c_{j}\right)}\right)+\beta_{i}\left(\delta^{b\left(c_{i}, c_{j}\right)}-A_{j}\left(c_{i}, c_{j}\right)\right)+\left(1-\beta_{i}\right) c_{i} \\
& =\beta_{i}-\beta_{i} A_{j}\left(c_{i}, c_{j}\right)+\left(1-\beta_{i}\right) c_{i}
\end{aligned}
$$

Substituting for $A_{j}\left(c_{i}, c_{j}\right)$ and rearranging leads us to the following result.

Lemma 5.6 Suppose that commitments are strictly positive, $c_{j}$ does not expire soon after $c_{i}$, and sum up to at most unity. Furthermore, suppose that $c_{i}+A_{j}\left(c_{i}, c_{j}\right) \leq 1$. Then, SPE payoffs in the bargaining subgame are given by:

$$
\begin{aligned}
& \pi_{i}=\beta_{i}+\left(1-\beta_{i}\right) c_{i}-\left(\beta_{i}-\beta_{i}^{2}\right) \delta^{\tau\left(c_{i}\right)}-\beta_{i}^{2} c_{j}+\left(\beta_{i}^{2}-\beta_{i}^{3}\right) \delta^{\tau\left(c_{j}\right)} \\
& \pi_{j}=1-\pi_{i}
\end{aligned}
$$

Remark 5.7 An important special case of Lemma 5.6 occurs when $c_{i}+A_{j}\left(c_{i}+c_{j}\right)=1$. Then, $b\left(c_{i}, c_{j}\right)=0$ and hence the payoffs are $\pi_{i}=c_{i}$ and $\pi_{j}=A_{j}\left(c_{i}, c_{j}\right)$.

In this section, we have established the SPE payoffs in the bargaining subgame - once the commitment levels are taken as given. Doing so, we have assumed that the players' commitments are strictly positive. The case with $c_{j}=0$ corresponds to the analysis in earlier sections of the paper, where only one player was committed.

We collect the findings of this section in the following theorem.

Theorem 5.8 Suppose that $c_{i} \geq c_{j}>0$. Then, in any SPE of the bargaining (sub-)game $G^{B}\left(c_{i}, c_{j}\right)$, payoffs are given by:

$$
\pi_{i}= \begin{cases}\beta_{i} \delta^{\tau\left(c_{j}\right)} & \text { if } \tau\left(c_{i}\right)>a\left(c_{j}\right), c_{i}+c_{j}>1 \\ \left(1-\beta_{i}\right) c_{i}-\beta_{i} c_{j}+\beta_{i} & \text { if } \tau\left(c_{i}\right)>a\left(c_{j}\right), c_{i}+c_{j} \leq 1 \\ \delta^{\tau\left(c_{i}\right)}-A_{j}\left(c_{i}, c_{j}\right) & \text { if } \tau\left(c_{i}\right) \leq a\left(c_{j}\right), c_{i}+A_{j}\left(c_{i}, c_{j}\right)>1 \\ \beta_{i}-\beta_{i} A_{j}\left(c_{i}, c_{j}\right)+\left(1-\beta_{i}\right) c_{i} & \text { if } \tau\left(c_{i}\right) \leq a\left(c_{j}\right), c_{i}+A_{j}\left(c_{i}, c_{j}\right) \leq 1\end{cases}
$$




$$
\pi_{j}= \begin{cases}\beta_{j} \delta^{\tau\left(c_{j}\right)} & \text { if } \tau\left(c_{i}\right)>a\left(c_{j}\right), c_{i}+c_{j}>1 \\ \beta_{j}-\beta_{j} c_{i}+\beta_{i} c_{j} & \text { if } \tau\left(c_{i}\right)>a\left(c_{j}\right), c_{i}+c_{j} \leq 1 \\ A_{j}\left(c_{i}, c_{j}\right) & \text { if } \tau\left(c_{i}\right) \leq a\left(c_{j}\right), c_{i}+A_{j}\left(c_{i}, c_{j}\right)>1 \\ \beta_{j}-\beta_{j} c_{i}+\beta_{i} A_{j}\left(c_{i}, c_{j}\right) & \text { if } \tau\left(c_{i}\right) \leq a\left(c_{j}\right), c_{i}+A_{j}\left(c_{i}, c_{j}\right) \leq 1\end{cases}
$$

In the second and fourth cases, SPE implies immediate and efficient agreement so that $\pi_{j}=1-\pi_{i}$. In the other cases, delay leads to an inefficiency.

\section{Optimal commitment for two players}

In the previous section, we have considered a bargaining game with given commitment levels. In what follows, we will find the optimal commitment choices. In a sense, we will now consider a game in which each player $k=1,2$ makes a choice $c_{k} \in[0,1]$ from a set of actions equal to the unit interval, and in which the payoff function is given by Theorem 5.8. In a first step, we will construct a function which assigns one player's bestresponse commitment to any commitment chosen by the other player. Then, we will use this best-response function to analyze the cases where players commit simultaneously and sequentially.

From now on, we will abandon the notational convention $c_{i} \geq c_{j}$. In Section 5 , we had used it to define the notion that the smaller commitment "expires soon after" the bigger one. We will now adopt the following terminology.

Definition 6.1 We will say that a commitment level $c_{i}$ is

$$
\begin{aligned}
& \text { 1. ... high if } 1-c_{i} \leq \varphi_{j} \delta^{\tau\left(c_{i}\right)} \text {; } \\
& \text { 2. ... intermediate if } 1-c_{i}>\varphi_{j} \delta^{\tau\left(c_{i}\right)} \text { but } c_{i}>\varphi_{i} \delta^{\tau\left(1-c_{i}\right)} \text {; } \\
& \text { 3. ... low if } c_{i} \leq \varphi_{i} \delta^{\tau\left(1-c_{i}\right)}
\end{aligned}
$$

If the commitment level $c_{i}>\frac{1}{2}$ is intermediate, then $1-c_{i}$ (the smaller commitment) expires soon after $c_{i}$. If the commitment $c_{i} \leq \frac{1}{2}$ is intermediate, then $c_{i}$ (the smaller commitment) expires soon after $1-c_{i}$. However, it need not always be true that a commitment which expires soon after its complement (or whose complement expires soon after it) is intermediate. The reason is that $\varphi_{i} \geq \psi_{i}$ may or may not hold with equality, depending on the values of $\beta$ and $\delta$.

We will now define a function $f_{j}$ which maps the commitment of player $i=1,2$ to a commitment for player $j \neq i$. It will then be shown that $f_{j}$ is $j$ 's best-response function. Let

$$
f_{j}\left(c_{i}\right)= \begin{cases}\psi_{j} \delta^{\tau\left(c_{i}\right)} & \text { if } c_{i} \text { is high } \\ 1-c_{i} & \text { if } c_{i} \text { intermediate } \\ \gamma_{j}\left(c_{i}\right) & \text { if } c_{i} \text { is low }\end{cases}
$$


where $\gamma_{j}\left(c_{i}\right)=\max \left\{c_{j} \mid c_{j}+A_{i}\left(c_{i}, c_{j}\right) \leq 1\right\}$.

Continue to denote by $\pi_{j}\left(c_{i}, c_{j}\right)$ the payoff of player $i$ in the SPE of $G^{B}\left(c_{i}, c_{j}\right)$. We will say that $c_{j}$ is a best-response to $\bar{c}_{i}$ if $\pi_{i}\left(\bar{c}_{i}, c_{j}^{*}\right) \geq \pi_{i}\left(\bar{c}_{i}, c_{j}\right)$ for all $c_{j}$. If the inequality holds strictly, then $c_{j}$ is the unique best-response to $\bar{c}_{i}$.

Theorem 6.2 The unique best-response of player $j$ to any commitment $c_{i}$ is given by the function $f_{i}\left(c_{j}\right)$.

Proof: Suppose first that $c_{i}$ is high. If $j$ follows $f_{j}\left(c_{i}\right)$, a payoff of $\varphi_{j} \delta^{\tau\left(c_{i}\right)}$ will result since $A_{j}\left(c_{i}, \psi_{j} \delta^{\tau\left(c_{i}\right)}\right)=\varphi_{j} \delta^{\tau\left(c_{i}\right)}$. Let us consider a commitment $c_{j}$ which leads to delay until round $\tau\left(c_{i}\right)$ at least. Among all such commitments, $\psi_{j} \delta^{\tau\left(c_{i}\right)}$ is uniquely optimal by the analysis in section 4 . Now consider the case where $j$ chooses any commitment $c_{j}$ which leads to an agreement before round $\tau\left(c_{i}\right)$. Then it must hold that $c_{j}<\psi_{j} \delta^{\tau\left(c_{i}\right)}$. Hence, we have that $c_{j}$ does not expire soon after $c_{i}$ and $c_{i}+A_{j}\left(c_{i}, c_{j}\right) \leq 1$, and under these conditions, Lemma 5.6 implies that player $j$ 's payoff is $\pi_{j}\left(c_{i}, c_{j}\right)=\beta_{j}\left(1-c_{i}\right)+\beta_{i} A_{j}\left(c_{i}, c_{j}\right)$. Since $c_{i}$ is high, it holds that $1-c_{i} \leq \varphi_{j} \delta^{\tau\left(c_{i}\right)}$. Furthermore, $A_{j}\left(c_{i}, c_{j}\right)<\varphi_{j} \delta^{\tau\left(c_{i}\right)}$. Consequently, $\pi_{j}\left(c_{i}, c_{j}\right)<\varphi_{j} \delta^{\tau\left(c_{i}\right)}$. Indeed, we have shown that $f_{j}$ gives the (unique) best-response to a high $c_{i}$.

Suppose that $c_{i}$ is intermediate, then $c_{i}$ expires soon after $1-c_{i}$ or $1-c_{i}$ expires soon after $c_{i}$, depending which is greater. Either way, if $j$ follows $f_{j}\left(c_{i}\right)$, payoffs of $c_{i}$ and $1-c_{i}$ will result. If $j$ instead chooses some $c_{j} \neq f_{j}\left(c_{i}\right)$ such that there will be delay until $\tau\left(c_{i}\right)$, then $j$ 's payoff is bounded above by $\varphi_{j} \delta^{\tau\left(c_{i}\right)}$. Since $c_{i}$ is intermediate, this is strictly less than $1-c_{i}$. Now suppose that $j$ chooses some $c_{j}$ such that agreement is reached in round $t<\tau\left(c_{i}\right)$. This requires $c_{i}+c_{j} \leq 1$. If $c_{i}>\frac{1}{2}$ and $c_{j}$ expires soon after $c_{i}$, then $\pi_{j}\left(c_{i}, c_{j}\right)=\beta_{j}\left(1-c_{i}\right)+\beta_{i} c_{j}$. Clearly, $c_{j}<1-c_{i}$ cannot be optimal. If $c_{i}>\frac{1}{2}$ and $c_{j}$ does not expire soon after $c_{i}$, then $\pi_{j}\left(c_{i}, c_{j}\right)=\beta_{j}\left(1-c_{i}\right)+\beta_{i} A_{j}\left(c_{i}, c_{j}\right)$. Since $A_{j}\left(c_{i}, c_{j}\right) \leq \varphi_{j} \delta^{\tau\left(c_{i}\right)}$ and $\varphi_{j} \delta^{\tau\left(c_{i}\right)}<1-c_{i}$, we have that $\pi_{j}\left(c_{i}, c_{j}\right)<1-c_{i}$. If $c_{i} \leq \frac{1}{2}$ and $c_{i}$ expires soon after $c_{j}$, then $\pi_{j}\left(c_{i}, c_{j}\right)=\beta_{j}\left(1-c_{i}\right)+\beta_{i} c_{j}$. Clearly, $c_{j}<1-c_{i}$ cannot be optimal. If $c_{i} \leq \frac{1}{2}$ and $c_{i}$ does not expire soon after $c_{j}$, then $c_{j} \geq 1-c_{i}$. But also $c_{i}+c_{j} \leq 1$, a contradiction to $c_{j} \neq 1-c_{i}$. We have now shown that $f_{j}$ gives the (unique) best-response to an intermediate $c_{i}$.

Suppose that $c_{i}$ is low. Consider first some $c_{j}$ such that $c_{j}>c_{i}$, and $c_{i}$ does not expire soon after $c_{j}$, and $c_{j}+A_{i}\left(c_{i}, c_{j}\right) \leq 1$. Among all such commitments, $\gamma_{j}\left(c_{i}\right)$ is uniquely optimal by construction. Now suppose that $c_{j}>c_{i}$, and $c_{i}$ does not expire soon after $c_{j}$, but $c_{j}+A_{i}\left(c_{i}, c_{j}\right)>1$. In this case, $\pi_{j}\left(c_{i}, c_{j}\right) \leq \delta^{\tau\left(c_{j}\right)}-A_{i}\left(c_{i}, c_{j}\right)$. Substituting for $A_{i}$, we obtain $\pi_{j}\left(c_{i}, c_{j}\right) \leq \beta_{j}\left(\delta^{\tau\left(c_{j}\right)}-c_{i}\right)+\beta_{i} \beta_{j} \delta^{\tau\left(c_{i}\right)}$. But by Theorem 3.6, it holds that $\pi_{j}\left(c_{i}, 0\right)=\beta_{j}\left(1-c_{i}\right)+\beta_{i} \beta_{j} \delta^{\tau\left(c_{i}\right)}>\pi_{j}\left(c_{i}, c_{j}\right)$. Now we see that $\gamma_{j}\left(c_{i}\right)$ is optimal among all those $c_{j}$ which are higher than $c_{i}$ and such that $c_{i}$ does not expire soon after $c_{j}$.

If $j$ chooses a $c_{j}$ such that $c_{j}$ expires soon after $c_{i}$ or $c_{i}$ expires soon after $c_{j}$, then his payoff is $\pi_{j}\left(c_{i}, c_{j}\right)=\beta_{j}\left(1-c_{i}\right)+\beta_{i} c_{j}$. Since this is expression is increasing in $c_{j}$, it will be without loss of generality to assume that $c_{j}>c_{i}$. Thus, we want to show that if $c_{j}>c_{i}$, and $c_{i}$ expires soon after $c_{j}$ and $c_{i}$ is low, then it holds that 


$$
\begin{aligned}
\pi_{j}\left(c_{i}, c_{j}\right) & <\pi_{j}\left(c_{i}, \gamma_{j}\left(c_{i}\right)\right) \\
\beta_{j}\left(1-c_{i}\right)+\beta_{i} c_{j} & <\beta_{j}\left(1-A_{i}\left(c_{i}, \gamma_{j}\left(c_{i}\right)\right)\right)+\beta_{i} \gamma_{j}\left(c_{i}\right) \\
\beta_{j}\left(A_{i}\left(c_{i}, \gamma_{j}\left(c_{i}\right)\right)-c_{i}\right) & <\beta_{i}\left(\gamma_{j}\left(c_{i}\right)-c_{j}\right) \\
\beta_{j}\left(\delta^{\tau\left(c_{j}\right)}-c_{i}-\beta_{j} \delta^{\tau\left(c_{i}\right)}\right) & <\gamma_{j}\left(c_{i}\right)-c_{j}
\end{aligned}
$$

Since $c_{i}$ expires soon after $c_{j}$ and $c_{j}>c_{i}$, we have that $c_{i}+\beta_{j} \delta^{\tau\left(c_{i}\right)}>\delta^{\tau\left(c_{j}\right)}$. Hence, the left-hand side of the above inequality is strictly negative. But $\gamma_{j}\left(c_{i}\right)-c_{j}>0$. Indeed, some $c_{j}$ such that $c_{i}$ expires soon after $c_{j}$ or $c_{j}$ expires soon after $c_{i}$ is not optimal if $c_{i}$ is low.

It remains to show that some $c_{j}<c_{i}$ which does not expire soon after $c_{i}$ is not optimal. Indeed, suppose that $c_{j}<c_{i}$ and $c_{j}$ does not expire soon after $c_{i}$. Then, $\pi_{j}\left(c_{i}, c_{j}\right)=$ $\beta_{j}\left(1-c_{i}\right)+\beta_{i} A_{j}\left(c_{i}, c_{j}\right)$. But $j$ could deviate to a commitment of $c_{j}^{\prime}=c_{i}$. Obviously, $c_{i}$ and $c_{j}^{\prime}$ expire at the same time and sum op to less than one. Hence, $\pi_{j}\left(c_{i}, c_{j}^{\prime}\right)=\beta_{j}\left(1-c_{i}\right)+\beta_{i} c_{j}^{\prime}=c_{i}$. Since $A_{j}\left(c_{i}, c_{j}\right)<c_{i}$, the choice of $c_{j}$ is not optimal. We have now shown that $f_{j}$ gives the (unique) best-response to a low $c_{i}$, which completes the proof.

By the sequential commitment game we mean the game in which player 1 initially chooses $c_{1}$, then player 2 chooses $c_{2}$, and then the bargaining game $G^{B}\left(c_{1}, c_{2}\right)$ is played. In the analysis of the sequential commitment game, we will write $\pi_{1}\left(c_{1}\right)$ for $\pi_{1}\left(c_{1}, f_{2}\left(c_{1}\right)\right)$, so that an SPE of the sequential commitment game corresponds to a maximum of $\pi_{1}\left(c_{1}\right)$. For player $i=1,2$, define $\eta_{i}=\max \left\{c_{i} \mid c_{i}+\varphi_{j} \delta^{\tau\left(c_{i}\right)} \leq 1\right\}$.

Theorem 6.3 For any $\delta$, the SPE division of the pie in the sequential commitment game is $\left(\eta_{1}, 1-\eta_{1}\right)$.

Proof: Suppose that player 1 chooses a high $c_{1}$. Then $f_{2}\left(c_{1}\right)=\psi_{2} \delta^{\tau\left(c_{1}\right)}$. Suppose further that $c_{1}+\varphi_{2} \delta^{\tau\left(c_{1}\right)}>1$. Then, the payoff to player 1 is $\pi_{1}\left(c_{1}\right)=\left(1-\varphi_{2}\right) \delta^{\tau\left(c_{1}\right)}<1-\varphi_{2}$. But $\pi_{1}(0)=1-\varphi_{2}$. We see that player 1 does not choose a high $c_{1}$ in SPE unless $c_{1}+\varphi_{2} \delta^{\tau\left(c_{1}\right)}=1$. But if the latter holds, then $c_{1}=\eta_{1}$.

Suppose that player 1 chooses an intermediate $c_{1}$. Then $f_{2}\left(c_{1}\right)=1-c_{1}$ and $\pi_{1}\left(c_{1}\right)=c_{1}$. By construction, $\eta_{1}$ is optimal among all intermediate $c_{1}$ if it is itself intermediate and strictly dominates all intermediate $c_{1}$ if it is itself high.

Finally, suppose that player 1 chooses a low $c_{1}$. Then $f_{2}\left(c_{1}\right)=\gamma_{2}\left(c_{1}\right)$ and $\pi_{1}\left(c_{1}\right) \leq$ $1-\gamma_{2}\left(c_{1}\right)$. We will complete the proof by showing that $\gamma_{2}\left(c_{1}\right) \geq \frac{1}{2}$ and $\eta_{1}>\frac{1}{2}$ and, therefore, $\pi_{1}\left(c_{1}\right) \leq \eta_{1}$. Suppose to the contrary that $\gamma_{2}\left(c_{1}\right)<\frac{1}{2}$ for some $c_{1}$. Then, by definition of $\gamma_{j}$, it holds that $\frac{1}{2}+A_{1}\left(c_{1}, \frac{1}{2}\right)>1$. But $A_{1}$ is defined as 1 's payoff in a subgame after round $\tau\left(c_{2}\right)$. Hence, $A_{1}\left(c_{1}, \frac{1}{2}\right)<\delta^{\tau\left(\frac{1}{2}\right)}<\frac{1}{2}$, a contradiction. Similarly, let us assume that $\eta_{1} \leq \frac{1}{2}$. Then, by definition of $\eta_{1}$, it holds that $\frac{1}{2}+\varepsilon+\varphi_{2} \delta^{\tau\left(\frac{1}{2}+\varepsilon\right)}>1$ for all $\varepsilon>0$. Then, $\varphi_{2} \delta^{\tau\left(\frac{1}{2}+\varepsilon\right)}>\frac{1}{2}-\varepsilon$ for all $\varepsilon>0$. Since $\delta^{\tau\left(\frac{1}{2}+\varepsilon\right)}<\frac{1}{2}+\varepsilon$, this implies that $\varphi_{2}>\frac{\frac{1}{2}-\varepsilon}{\frac{1}{2}+\varepsilon}$ for all $\varepsilon>0$. But for any $\beta$ and $\delta$, it holds that $\varphi_{2}<1$, a contradiction.

Passing to the limit as $\delta \rightarrow 1$ yields the following prediction. 
Theorem 6.4 In the limit as $\delta$ goes to one, the SPE division of the pie in the sequential commitment game converges to $\left(x_{1}, x_{2}\right)=\left(\frac{2-\beta_{2}}{3-\beta_{2}}, \frac{1}{3-\beta_{2}}\right)$.

If commitments were irrevocable and lasted forever, one would expect the first-mover to obtain the entire surplus. With the notion of commitment under consideration in this paper, this is still true if $\delta$ is close to zero. However, for large $\delta$, the second-mover can secure at least one third of the surplus.

By the simultaneous commitment game we mean the game in which initially players 1 and 2 simultaneously choose their commitment levels $c_{1}$ and $c_{2}$, and then the bargaining game $G^{B}\left(c_{1}, c_{2}\right)$ is played. In this game, the pair $\left(c_{1}, c_{2}\right)$ is an SPE if it holds that $f_{i}\left[f_{j}\left(c_{i}\right)\right]=$ $c_{i}$ for $i=1,2$ and $j \neq i$. Since $f_{j}\left(c_{i}\right)=1-c_{i}$ for intermediate $c_{i}$, Theorem 6.2 and Lemma 5.3 imply the following.

Corollary 6.5 If $c_{1}$ and $c_{2}=1-c_{1}$ are both intermediate, then there is an SPE of the simultaneous commitment game in which commitments and payoffs are equal to $c_{1}$ and $c_{2}$.

Whether a given commitment is intermediate depends on the discount factor. It follows from Definition 6.1 that, for $\delta$ sufficiently close to zero, a commitment $c_{i}$ is intermediate if and only if $c_{i} \in(0,1)$, and that, for $\delta$ sufficiently close to one, a commitment $c_{i}$ is intermediate if and only if $c_{i} \in\left(\frac{1}{3-\beta_{i}}, \frac{2-\beta_{j}}{3-\beta_{j}}\right)$.

Lemma 6.6 If $f_{i}\left[f_{j}\left(c_{i}\right)\right]=c_{i}$ and $c_{i}$ is high (low), then $f_{j}\left(c_{i}\right)$ is low (high).

Proof: Suppose that $c_{i}$ is high and $f_{i}\left[f_{j}\left(c_{i}\right)\right]=c_{i}$. It is easy to see that $f_{j}\left(c_{i}\right)$ cannot be high. (Otherwise, we would have $\psi_{i} \delta^{\tau\left[\psi_{j} \delta^{\tau\left(c_{i}\right)}\right]}=c_{i}$, which is impossible since $c>\delta^{\tau(c)}$ for any $c$.) If $f_{j}\left(c_{i}\right)$ is intermediate, then $c_{i}$ satisfies the fixed point condition $c_{i}=1-f_{j}\left(c_{i}\right)=1-\psi_{j} \delta^{\tau\left(c_{i}\right)}$. Again, we obtain a contradiction since $f_{j}\left(c_{i}\right)=\psi_{j} \delta^{\tau\left(1-f_{j}\left(c_{i}\right)\right)}$ means that $f_{j}\left(c_{i}\right)$ is low rather than intermediate. We have shown the first part of the lemma.

Suppose now that $c_{i}$ is low and $f_{i}\left[f_{j}\left(c_{i}\right)\right]=c_{i}$. Since $\gamma_{j}\left(c_{i}\right)>c_{i}$, it is clear that $f_{j}\left(c_{i}\right)$ cannot be low. Suppose that $f_{j}\left(c_{i}\right)=\gamma_{j}\left(c_{i}\right)$ is intermediate. Then, the fixed point condition becomes $c_{i}=1-\gamma_{j}\left(c_{i}\right)$. Since $A_{i}\left(c_{i}, c_{j}\right) \geq c_{i}$, we have $\gamma_{j}\left(c_{i}\right)+A_{i}\left(c_{i}, c_{j}\right) \geq 1$. By definition of $\gamma_{j}$, it follows that $\gamma_{j}\left(c_{i}\right)+A_{i}\left(c_{i}, c_{j}\right)=1$. But then, $\varphi_{i} \delta^{\tau\left[\gamma_{j}\left(c_{i}\right)\right]} \geq 1-\gamma_{j}\left(c_{i}\right)$, implying that $\gamma_{j}\left(c_{i}\right)$ is high, a contradiction.

Lemma 6.7 The division $\left(\eta_{i}, 1-\eta_{i}\right)$ can be supported by an SPE of the simultaneous commitment game.

Proof: Suppose first that there exists a $c_{i}$ such that $c_{i}+\varphi_{j} \delta^{\tau\left(c_{i}\right)}=1$. Then, $c_{i}=\eta_{i}$, and $\eta_{i}$ is high. Thus, $f_{j}\left(\eta_{i}\right)=\psi_{j} \delta^{\tau\left(\eta_{i}\right)}$. But since $A_{j}\left(c_{i}, \psi_{j} \delta^{\tau\left(c_{i}\right)}\right)=\varphi_{j} \delta^{\tau\left(c_{i}\right)}$, it holds that $\gamma_{i}\left[f_{j}\left(\eta_{i}\right)\right]=\gamma_{i}\left[\psi_{j} \delta^{\tau\left(\eta_{i}\right)}\right]=1-\varphi_{j} \delta^{\tau\left(c_{i}\right)}$. Indeed, we have shown that $\eta_{i}=f_{i}\left[f_{j}\left(\eta_{i}\right)\right]$.

Now suppose that there does not exist $c_{i}$ such that $c_{i}+\varphi_{j} \delta^{\tau\left(c_{i}\right)}=1$. Then, $\eta_{i}+\varphi_{j} \delta^{\tau\left(\eta_{i}\right)}<$ 1. Hence, $\eta_{i}$ is intermediate, in which case the claim follows from Corollary 6.5. 
Theorem 6.8 A division $\left(x_{1}, x_{2}\right)$ can be supported by an SPE of the simultaneous commitment game if and only if $x_{1}+x_{2}=1$ and, moreover, it holds that $x_{i} \geq 1-\eta_{j}$ for both $i=1,2$ and $j \neq i$.

Proof: If: Follows from Corollary 6.5 and Lemma 6.7.

Only If: Suppose that $f_{1}\left[f_{2}\left(c_{1}\right)\right]=c_{1}$. By Lemma 6.6, there are two cases two distinguish: Either $c_{1}$ and $c_{2}$ are both intermediate, or one of them is high and the other low. Suppose first that $c_{1}$ and $c_{2}$ are both intermediate. Then, $c_{1}+c_{2}=1$ by Theorem 6.2 , and furthermore each player receives his commitment. But by definition, an intermediate $c_{i}, i=1,2$ satisfies $c_{i}+\varphi_{j} \delta^{\tau\left(c_{i}\right)}<1$, and thus $c_{i} \leq \eta_{i}$. But since commitments sum up to one, $c_{j} \geq 1-\eta_{i}$ for $j \neq i$. Now consider the case where one player has a low commitment and the other a high commitment. Suppose without loss of generality that $c_{i}$ is high and $c_{j}$ is low. Then, the fixed point condition becomes $c_{i}=\gamma_{i}\left[\psi_{j} \delta^{\tau\left(c_{i}\right)}\right]$, in which case $c_{i}=\eta_{i}$. But then, the division of the pie is $\left(\eta_{i}, 1-\eta_{i}\right)$, as desired.

In the simultaneous commitment game, there is a range of divisions of the surplus which can be supported by SPE. The endpoints of the range are the divisions that correspond to the equilibrium of the sequential commitment game with either player as the first mover.

Passing to the limit as $\delta \rightarrow 1$, we find the following equilibrium range.

Theorem 6.9 If $\delta$ is sufficiently close to one, the pie division $x$ can be supported by an SPE of the simultaneous commitment game if and only if $x$ is efficient $\left(x_{1}+x_{2}=1\right)$ and, moreover, it holds that $x_{i} \geq \frac{1}{3-\beta_{i}}$ for both $i=1,2$.

With the conventional notion of irrevocable share-commitments, one would expect the simultaneous commitment case to be a mere coordination problem in which any distribution can be supported by some equilibrium. In the model at hand, this is still true if $\delta$ is close to zero. However, if $\delta$ is close to one, the range of equilibrium divisions shrinks considerably. More precisely, in the limit as $\delta \rightarrow 1$, the share of the surplus whose allocation is left unpredicted by SPE is at most one fifth. Conversely, for large $\delta$, SPE is sufficiently strong as a solution concept to determine eighty percent of the allocation. Moreover, we note that each player's share is bounded below by one third, even with arbitrarily low recognition probability.

Comparing the results for the sequential and simultaneous commitment games, two common points emerge.

First, our model yields predictions tantamount to what one would expect with irrevocable, everlasting commitments if $\delta$ is close to zero, but produces very different results if $\delta$ is close to one. The intuition is that with a small $\delta$, the option to hold out until the opponent's commitment becomes void is very unattractive and hence commitment confers a lot of power.

Second, for large $\delta$, the ability to make a commitment of the type which we propose ensures that a player will get at least one third of the surplus, even if his recognition probability is arbitrarily small. In a sense, the ability to commit is worth one third of the surplus to each player, while the value of proposal power lies in determining the allocation of the remaining third. 
Theorem 6.10 A pie division $x$ can be supported by an SPE of the simultaneous commitment game for all $\delta$ and for all $\beta$ if and only if $x$ is the equal split solution.

Proof: If: By definition of $\tau$, we have that $\delta^{\tau\left(\frac{1}{2}\right)}<\frac{1}{2}$. Moreover, $\varphi_{k}<1$ for $k=1,2$. As a result, $\varphi_{k} \delta^{\tau\left(\frac{1}{2}\right)}<\frac{1}{2}$ for both $k=1,2$. We see that a commitment of $\frac{1}{2}$ is always intermediate. Corollary 6.5 implies the claim.

Only if: Consider a pie division in which player $k=1,2$ obtains a payoff of $\frac{1}{2}-\varepsilon$, where $\varepsilon>0$. By Theorem 6.9, if $\delta$ is sufficiently large, SPE requires $\frac{1}{2}-\varepsilon \geq \frac{1}{3-\beta_{k}}$. This can be rewritten as $\beta_{k} \leq \frac{\frac{1}{2}-3 \varepsilon}{\frac{1}{2}-\varepsilon}$. But we have assumed that $\varepsilon>0$, thus $\frac{\frac{1}{2}-3 \varepsilon}{\frac{1}{2}-\varepsilon}<1$. Consequently, choosing $\delta$ sufficiently large and $\beta_{k} \in\left(\frac{\frac{1}{2}-3 \varepsilon}{\frac{1}{2}-\varepsilon}, 1\right)$ ensures that the pie division under consideration is no SPE.

Theorem 6.10 establishes the equal split solution as an appealing focal point. Any allocation can be obtained as an SPE of the simultaneous commitment game for some choices of $\beta$ and $\delta$. However, the equal split solution is unique in being consistent with SPE for any $\beta$ and $\delta$.

\section{Conclusion}

We have studied the division of a shrinking surplus through a bilateral bargaining procedure with commitment. The notion of commitment which we have proposed is new in the sense that a commitment expires when it has become infeasible. If only one player can commit, we find that such commitment is a source of bargaining power only for sufficiently large values of the discount factor. If one player has a high recognition probability, the opponent's ability to commit is just sufficient to offset the proposal power advantage. This is a more nuanced result than what would be obtained under perfect commitment, which would effectively turn the strategic situation into an ultimatum game. If both players make a commitment one after the other, then the share of the first mover is uniquely predicted by the subgame perfect equilibrium concept, and it varies between one half and two thirds of the pie, depending on recognition probabilities. If both players can simultaneously commit, a traditional notion of perfect commitment has no predictive power since any efficient division can be reached in equilibrium. Under the notion of commitment proposed here, however, the range of divisions consistent with perfect equilibrium shrinks considerably in the limit as the discount factor goes to one. In fact, the allocation of at most twenty percent of the pie remains unpredicted by the standard perfect equilibrium concept in the limit. Moreover, it turns out that the equal split solution is consistent with equilibrium for any choice of the discount factor and the recognition probabilities. Conversely, the equal split is the only division with this property. 


\section{References}

Abreu, D. And F. Gul (2000) ,"Bargaining and reputation," Econometrica, 68, 85-117.

Calabuig, V., A. Cunyat, and G. Olcina (2002), "Commitment and choice of partner in a negotiation with a deadline," Spanish Economic Review, 4, 61-87.

Cunyat, A. (2004) "The optimal degree of commitment in a negotiation with a deadline," Economic Theory, 23, 455-465.

Fershtman, C. and D. Seidmann (1993), "Deadline effects and inefficient delay in bargaining with endogenous commitment," Journal of Economic Theory, 60, 306-321.

Kambe, S. (1999) ,"Bargaining with imperfect commitment," Games and Economic Behavior, 28, 217-237.

LI, D. (2007) ,"Bargaining with history-dependent preferences," Journal of Economic Theory, 136, 695-708.

Muthoo, A. (1992) ,"Revocable commitment and sequential bargaining," The Economic Journal, 102, 378-387.

Muthoo, A. (1996) ,"A bargaining model based on the commitment tactic," Journal of Economic Theory, 69, 134-152

NASH, J.F. (1953) ,"The bargaining problem," Econometrica, 18, 155-162.

Rubinstein, A.(1982) ,"Perfect equilibrium in a bargaining model," Econometrica, 50, 97-109.

Shaked, A. And J. Sutton (1984) , "Involuntary Unemployment as a Perfect Equilibrium in a Bargaining Model," Econometrica, 52, 1351-1364. 